\title{
The Research on Higher Vocational and Technical Education of Electric and Electronic Discipline
}

\author{
Ran Jia ${ }^{1, a}$, Miao $\mathrm{Li}^{2, \mathrm{~b}}$ \\ 1,2Baoding Vocational and Technical College, Mechanical and Electrical Engineering, Baoding, \\ Hebei Province, 071000
}

Keywords: Higher Vocational and Technical Education, Electric and Electronic Discipline

\begin{abstract}
The role and status of vocational and technical education have got recognition and attention in recent years and it has become an important part of higher education. The electric and electronic discipline occupies a large proportion in our higher education institutions particular in engineering colleges. Therefore, in higher vocational and technical education of electrical and electronic class, it should be combined with China's actual situation and make a serious and realistic analysis. It is necessary to carry forward the characteristics of traditional education in our country, but also to learn and absorb all advanced educational achievement abroad. Only adhere to the requirements of the above theory, the vocational and technical education of electrical and electronic can meet the needs of modern economic development.
\end{abstract}

\section{Introduction}

When carrying out the basic theory of teaching vocational education, is "necessary, enough" principle, the curriculum and content must be determined according to the needs of professional positions, courses to emphasize the relevance of professional proficiency and skills, and therefore In the process of teaching cannot be too much emphasis on the systematic and interdisciplinary theory, but should focus on the actual use and professional technical theory, by teaching applied science and technology, culture and practical professionals. For example, electrical machines equipment repair, there is no need to learn the factory power supply, high-frequency circuits and other courses, but should be added to the machine and low voltage electrical courses. Higher education emphasizes students' practical ability, and therefore specific teaching process should pay attention to the practical teaching, so that students have the ability to solve practical problems. This requires as a practical teaching tasks teacher should have a wealth of practical experience; professional theory courses as teachers, in addition should have a certain expertise, but also has some professional experience. In short, the need for education from the socio-economic development of vocational departure, note research, a broad understanding of the types of jobs in new industries, job requirements, closely tracking developments and trends in high-tech, in the teaching process constantly replenished latest content [1].

\section{The Problems and Solutions of Electrical and Electronic in Higher Vocational and Technical Education}

Electrical Information and Related reference "electrical" professional, in our institutions of higher learning in engineering colleges in particular, occupies a large proportion of the professional. For a long time, the culture of the local colleges and universities in particular electrical talents of ordinary institutions of information, they use a "theoretical classroom teaching + classroom teaching experiment" based model, this teaching model is the biggest drawbacks of poor practice teaching. Despite the open experiment, comprehensive experiment, course design, graduation practice, graduation design practice teaching to some extent make up for the lack of practical teaching system on the model, but in recent years due to the severe employment situation, making the graduation practice, graduation design practice teaching severely impact the corresponding teaching effect is greatly reduced, eventually leading to relatively poor students practical ability, innovation is difficult 
to meet the demand for talent in today's society. For local ordinary institutions in the western region, due to the restrictions of students, hardware, teachers and other conditions, it is particularly prominent in this regard. So, how in just four years, the maximum train practical ability and innovation ability, higher education workers must seriously think about [2].

\section{The Establishment of Science and Technology Innovation Activity Long-Term Mechanism Based on Academic Competitions}

Resources integration. Our hospital each department have organized students to participate in "National Mathematical Contest in Modeling," and the "Challenge Cup" and other national and provincial competitions. In addition, the relevant Department of the Ministry also hosts regular hospital-wide electronic design contest, and mathematical modeling contest, software design competitions. In recent years, under the unified planning Academy, we integrate the space, equipment, teachers and other resource-related portion of the system, in the organization and management of academic competitions, campus culture construction technology, the relevant teaching units of mutual cooperation and joint management, the formation of a force, creating a new situation of campus technology innovation culture [3].

Bases construction Students' science and technology innovation base is to carry out the material basis and the main conditions for science and technology disciplines contest and campus culture construction. Our school established the "Electrical and Information Innovation Lab," and as a base to carry out the relevant professional academic competitions and extracurricular science and technology activities. Since then, the institute has been established in more than one service to science and technology activities and student extracurricular activities, academic competitions Open Lab. College from both hard and soft conditions resources to provide quality service platform for college students to scientific and technological innovation. By improving the working system and establish an incentive mechanism to increase funding, schools and enterprises to build laboratories, etc., to create a vibrant majors Electric Information Science and Technology Innovation Activities base. In the college's leadership, the hospital Communist Youth League of unified planning, the relevant teaching units involved in specific management base by the students' independent work.

Incentives. Students are the main academic competitions, but also the direct beneficiaries of academic competition. In recent years, the hospital has adopted various measures to mobilize students to participate in academic competitions population enthusiasm, train a number of key elements and has played a leading and exemplary role. In order to encourage students to participate in academic competitions enthusiasm, some of our practices include: 1 . Set innovation credits. Students can participate in a variety of research work, academic activities, academic competitions, published papers and books and other ways to get at least four of innovation credits. 2. Establishment of innovation scholarships for students in recognition of outstanding scientific and technological innovation and collective activities. 3. On the academic assessment, set a certain preferential policies.

Protection mechanism. Students safeguard mechanism is a prerequisite to ensure depth and sustained technological innovation activities can be pursued, our approach is to: 1. Establish financing mechanisms. Our hospital has always attached importance to carry out extracurricular science and technology activities, each year some earmarks for development and competitions in various disciplines at all levels of the organization and training of student extracurricular science and technology activities. In addition, we also scientific and technological activities through a variety of channels to raise funds, such as corporate sponsorship, part of the proceeds and other funding and student teachers in science and technology services to obtain research funding. 2. Introduction of project-based mechanisms. Students actively explore scientific training methods, the implementation of the project and participation system. Actively encourage students to combine their own characteristics and advantages, and actively participate in teacher research, research and development company involved in the project. 3. Subject contest into daily teaching activities. In recent years, our hospital electrical information related professional in revising the teaching program, have consciously close contest with the subject into the normal course of personnel training programs. 4 . 
Rationalize the relationship between the relevant departments and teaching units. Correctly handle the relationship between House Committee, Office of Academic Affairs and relevant teaching units, innovation base, give full play to the guiding role management functions and improve the degree of participation of the various teaching units, depth and active participation.

Construction of instructor team. Build a sense of professionalism, high professional level, experienced, dedicated innovation base instructor team, a college student science and technology innovation can continue to carry out the important guarantee. 1. Leadership attention and care. Guide students to engage in science and technology innovation, requires the instructor to pay a lot in terms of time and effort, for various reasons, this is unlikely to pay the corresponding material rewards, and therefore, in addition to the guidance of teachers with selfless devotion and dedicated to the work, but also our homes, department leaders focus on the instructor's emotional involvement, even personally involved in the work in the past. 2. The establishment of science and technology innovation Tutorial. Our approach is mainly used "Teacher + Student" and "division with only" mode, one (or several) instructors and students constitute a plurality of scientific and technological activities of the group, each group independently carry out scientific and technological innovation. 3. Develop a reasonable workload and contest winner instructor workload calculation method, the teacher's guidance into sector performance appraisal system [4].

\section{Foster Distinctive Campus Scientific Culture}

School-enterprise cooperation, mutual benefit and win-win campus technology culture construction mode. Thanks to college geographical advantages and the "city school is compatible, school-enterprise cooperation," the guiding ideology, cultural and scientific and technological innovation majors electrical information in our hospital, but also gradually formed a school-enterprise cooperation, mutual benefit and win-win situation well, some of practices and thinking as follows: 1 . the establishment of school-enterprise cooperation committee mechanism, and related businesses to build a science and technology innovation base. Build a school-enterprise cooperation, total business innovation base, will help create an atmosphere in the workplace at the base, by introducing a real project business, on the one hand can improve students' enthusiasm to participate in science and technology innovation, improve personnel training base effect; On the other hand, the students study a certain extent, also give the company's product development provides a wide range of underlying technical support, innovative and strong research even used for business. 2. Long-term hire local backbone enterprises of outstanding engineering and technical staff for innovation base instructor, the selection of outstanding students directly participate in the project development. By enterprises to participate in innovation base team composition mode gradually from a single "school teachers + students" model, expanded to contain "Engineer + student" and "teacher + school Engineer + student" multi-mode coexist. 3. Regularly engage business executives or technical experts to the schools to organize various forms of lectures, so that students learn more about the local economy and focus on building boom. 4. To strengthen scientific innovation activities and social practice combination. Organize students to carry out social surveys, to business and community involvement technical services, increase the technology content of social practice, and expand the content and scope of scientific and technological activities [5].

The student self-management and independent running innovation base development model. The construction and development of students' innovation base, by its very nature independent of college students practice on a culture of innovation. Base is a "student organizations", and a "laboratory." I actively encourage students to participate in hospital management efforts innovation base, so that the innovative practices as far as possible to the students to independently design, self-organization to complete the progressive realization of scientific and technological innovation base student self-management, the goal of independent operation, give full play to science and technology innovation the main role of the activities of middle school students. To achieve this goal, the work currently carried out by the hospital include: 1 . Construction of a complete student management team. Base student management team should contain the "base Chairman" and other 
positions, including all composed by the students, "liaison", "project unit" and other sectors. 2. The construction most favorable to the student management system to carry out scientific and technological activities. So that students can have a relaxed time and space as much as possible into the innovation lab environment, not limited in time, take the "low threshold" access system. 3 . The creation of appropriate equipment conditions, so that students can independently design in the laboratory, the independent test, independent play, self-observation, self-analysis and summary.

Product development and competition-oriented project introduction mode. Project activities to introduce scientific and technological innovation mechanism, must proceed from reality, according to the characteristics of the school to develop the school. In accordance with this principle and idea, in recent years, the introduction of electronic information specialty hospital technological innovation activities, the use of a "product development" and "academic competitions" oriented combination model. 1. "Product development" as the guide, is that students choose topics science and technology innovation to transform the company's existing products or develop new products, mainly to strengthen the scientific and technological innovation activities targeted to stimulate the interest of students to participate. 2. "discipline competition" as the guide mode, is through the national or provincial level academic competitions topic in-depth research, forecasting types of questions that may arise at the next race, and this configuration issues, science and technology activities and expand Contest Training this is "false questions really do" mode.

\section{Conclusion}

In the higher vocational and technical education of electrical and electronic class, we should require students to master the applied technology theory and take the "competence center" teaching mode to cultivate students. Academic competitions and campus technology culture construction are effective ways to train the practical ability and innovation ability of college students majored in electrical electronic. It should be based on the characteristics of electrical engineering, break down a variety of professional ability and put into the curriculum. And we can also through a series of purposeful, step of capacity-building and training to enhance the students' skills to identify problems, analyze problems and solve problems and train more creative talents with innovation sense for the community.

\section{References}

[1] S.K.Yu, The creation of college students' science and technology innovation ability training patterns, J. Vocational and Technical Education, 5(2008) 46-47.

[2] S.Yi, Build multidisciplinary contest platform to train new talents, J. Experimental Technology and Management. 5(2009) 26-30.

[3] H.X.Chang, Thoughts and practice of training and developing students' creativity, J. Vocational and Educational. 12(2009) 56-58.

[4] H.P.Huo, Create a campus culture of science and technology to implement the quality education, J. Occupation and Education .9(2009) 19-22.

[5] W.B.Zeng, Construction and practice of electric information innovation laboratory, J. Guangxi Technology University. 4(2005) 129-132. 